\title{
Editorial: Bridging the Gap between Policy and Science in Assessing the Health Status of Marine Ecosystems
}

\author{
Angel Borja ${ }^{1 *}$, Michael Elliott ${ }^{2}$, María C. Uyarra ${ }^{1}$, Jacob Carstensen ${ }^{3}$ and Marianna Mea ${ }^{4}$ \\ ${ }^{1}$ AZTI-Tecnalia, Marine Research Division, Pasaia, Spain, ${ }^{2}$ Institute of Estuarine and Coastal Studies, University of Hull, Hull, \\ UK, ${ }^{3}$ Department of Bioscience, Aarhus University, Roskilde, Denmark, ${ }^{4}$ Ecoreach, Ancona, Italy
}

Keywords: environmental status, monitoring, modeling, assessment, marine strategy framework directive

\section{Editorial on the Research Topic}

\section{Bridging the Gap between Policy and Science in Assessing the Health Status of Marine} Ecosystems

There is a continuing requirement in all environments for science to inform policy and policy to inform science and these interactions have created an expanding and fast-moving field. Furthermore, new research and new policy requirements continually change the demands both on policy makers and scientists and both groups need to be well-informed about their own and other fields. Marine management is no different from that in any other environment, albeit perhaps more complex and interrelated, and as such it requires approaches which bring together the best research from the natural and social sciences. It requires stakeholders to be well-informed by science and to work across administrative and geographical boundaries, a feature especially important in the inter-connected marine environment. It also requires us to be clear regarding the nature and role of stakeholders, especially if all groups are to be engaged to achieve a sustainable marine system which can deliver a healthy ecosystem and the economically-based "Blue Growth" required by society.

Given these demands, marine management must ensure that the natural structure and functioning of ecosystems is maintained to provide ecosystem services. Thus, once provided by ecosystem processes, the ecosystem services can lead to the delivery of societal goods and other benefits as long as society inputs human complementary assets such as its skills, time, money and energy to gather those benefits. The economic benefits obtained from the seas thereby constituting Blue Growth, which is currently demanded by policy-makers and politicians worldwide. However, if sufficient societal goods and other benefits are to be obtained, society requires appropriate administrative, legal and management mechanisms (i.e., the right laws and management agencies) to ensure that exploiting such benefits does not impact on environmental quality, but instead supports the sustainable use of our seas.

Therefore to achieve the goal of "Bridging the Gap Between Policy and Science in Assessing the Health Status of Marine Ecosystems" there is the need to find a common ground in which scientists should advance their science and provide policy makers with the best available and timely knowledge. This cannot be achieved without a sound and detailed knowledge and interpretation of the functioning of marine ecosystems. Hence, policy makers, recognizing the complexity and vulnerability of this system, should, through informed decisions, establish and implement a framework for the environmentally sustainable exploitation of the seas by society. To ensure that this is achieved, adequate, timely and fit-for-purpose monitoring is needed. For that monitoring to be meaningful and effective, it should be carried out against both quantitative and qualitative indicators and using fit-for-purpose methods. This in turn will enable scientists and managers to determine trends in the system and assess whether previously implemented management actions are successful. 
The assessment and management of large marine areas is particularly challenging given the transboundary nature of marine problems and uses but is required especially to deliver Blue Growth and expand the Blue Economy. Despite the importance of this, given current economic restrictions, all of this has to be achieved in a cost-effective and cost-beneficial manner. However, it is particularly notable that many countries do not now have (or are not willing to commit) the sufficient financial resources to fully assess the state of the marine environment.

With all of this in mind, in 2012, EU policy-makers and regulators funded a research project on the "DEVelopment Of innovative Tools for understanding marine biodiversity and assessing good Environmental Status" (DEVOTES: http://www. devotes-project.eu), under the 7th Framework Programme "The Ocean of Tomorrow" Theme. The funders required that the expected impacts from accepted proposals should "contribute to the implementation of the Marine Strategy Framework Directive (MSFD) and associated Commission Decision on Good Environmental Status (GES) and strengthen the knowledge base necessary to address sustainable management of seas and oceans resources." Hence, any selected project was required to contribute to bridge the gap between policy (i.e., the MSFD) and science (in this case, the creation of indicators, models, assessment tools, etc.), by increasing the knowledge necessary to assess the marine environmental status in an effective manner.

Given the interrelated nature of the features of seas and transnational marine management, tackling the marine problems requires a multidisciplinary team covering multinational continental sea areas. In the case of European seas, this needed a focus on strong collaboration among European institutions, regional seas as well as overseas partners, to achieve the much-needed synergies in research. Hence, the DEVOTES project encompassed 295 scientists from 23 institutes and 15 countries, including observers from the United States and an Advisory Board with members from Canada, the European Commission and the European Regional Seas Conventions. Further collaboration with other European and national projects was initiated during the 4 year lifespan of DEVOTES (2012-2016) (see Mea et al. in this eBook). As a measure of its wide reach, this internal and external collaboration has resulted in 32 Ph.D students trained, 4 stakeholder workshops, 9 scientific sessions organized in international conferences, 27 post-graduate training courses, 6 training courses on the tools developed, 4 summer schools, 424 contributions to conferences, and to date over 180 scientific papers, 31 of which are included in this ebook (see details in Mea et al.).

Successful scientific dissemination and the wider use of the science carried out requires a commitment to publishing our research in open access outlets, and in making our results available to scientists, stakeholders, policy-makers and the society at large. As such, all DEVOTES deliverables are publicly available (http://www.devotes-project.eu/deliverablesand-milestones/), as are the software and tools produced under DEVOTES (http://www.devotes-project.eu/software-and-tools), and all our papers are in gold or green open access (http://zenodo. org/collection/user-devotes-project). However, with the aim of bridging the communication gap between science and policy, the scientific knowledge generated in DEVOTES has also been communicated to policy makers through policy briefs, local press releases, fit-for-purpose workshops/webinars and conferences, etc. (see details in Mea et al.).

With the above in mind, we took the view that a Research Topic in Frontiers in Marine Science would be an ideal platform for synthesizing and promoting up-to-date research in marine science and management. Accordingly, this led to this volume giving the results from DEVOTES as well as other projects developing tools to improve marine management, and putting these into a global context. Therefore, this volume allowed the scientific community to contribute their research worldwide to advance the knowledge on assessing health status of marine ecosystems. Hence, this Research Topic is the result of this effort by including investigations from the DEVOTES project published in Frontiers in Marine Science between 2014 and 2016 (Andersen et al., 2014; Borja, 2014; Borja et al., 2014, 2016; Carstensen, 2014; Galparsoro et al., 2014), together with new syntheses and reviews (Cochrane et al.; Smith et al.; Lynam et al.; Danovaro et al.; Heiskanen et al.; Teixeira et al.; Mea et al.; Borja et al., 2016; Borja et al.) and original research (e.g., Newton and Elliott; Korpinen and Andersen; Patricio et al.; Patricio et al.; Ferrera et al.; Aylagas et al.; Aylagas et al.; Queiros et al.; Uusitalo et al.). We have also included studies from external research groups which complement the DEVOTES studies (Chartrand et al.; Callaway; Gago et al.; Dietl et al.; Noble et al.).

Following the production of the First Edition of this eBook, and as a reflection of the fast-moving and innovative nature of the field covered, other contributions have now been added to this greatly expanded Second Edition. As with the First Edition, which has been well-received, with plenty of downloads, the contributions are structured as follows. Firstly, the Introduction explains the background of the Research Topic and introduces the grand challenges in marine ecosystems ecology (Borja, 2014), some of which have been addressed within the DEVOTES project and so are included in this eBook.

Secondly, we give the legal and administrative framework of marine activities and management, including the efforts made in the past 20 years in developing a unified framework for marine management (Patricio et al.); the conceptual models used in managing the marine environment (Smith et al.), and a global review of cumulative pressure and impact assessment (Korpinen and Andersen). This section also includes the first published typology of stakeholders involved in marine environmental management (Newton and Elliott) as well as guidance for stakeholder involvement. Finally, we have included some modeling tools required to implement the MSFD (Lynam et al.).

Thirdly, the need for fit-for-purpose monitoring is especially shown by first understanding and assessing current European Marine Biodiversity Monitoring Networks (Patricio et al.), then developing innovative monitoring methods. The latter includes the use of new molecular methods in monitoring picoplankton (Ferrera et al.) and macroinvertebrates (Aylagas et al.); the use of historical data in studying benthic fauna (Callaway); the application of sclerochronology to monitoring (Steinhardt et al.); the development of a new biosensor as an early warning signal of pollution (Andrade et al.), and the monitoring of microplastics (Gago et al.). All of this is presented with the aim of ensuring that we can monitor the sustainable provision of marine 
ecosystem services (Carstensen, 2014) and so we have included all innovative methods developed under the DEVOTES project (Danovaro et al.).

Fourthly, there is the need for good monitoring data linked to indicators to assess the environmental status of marine ecosystems. Hence, we present a review of the current use of indicators in Europe (Heiskanen et al.; Teixeira et al.), together with an objective framework to test the quality of candidate indicators of good environmental status (Queiros et al.). However, indicators need adequate thresholds, and so these are described, for example, in a study on thresholds to prevent dredging impacts on seagrasses (Chartrand et al.). With regard to other contemporary marine challenges, the assessment of ballast water exchange compliance is discussed (Noble et al.) as is the food-web assessment in the Baltic Sea (Lehtinen et al.). The link between seagrasses and seabirds is presented (Balsby et al.) together with the prediction of the composition of polychaete assemblages (Galanidi et al.) and mollusc assemblages (Dietl et al.). Furthermore, we have included the development of a new non-indigenous species indicator (Olenin et al.).

Fifthly, a solid framework is required to assess environmental status in an integrative way but by focusing on the central theme of biodiversity protection. The latter requires a good and accepted understanding of biodiversity (Cochrane et al.). The aim to create such an integrated assessment requires us to consider different ways in which multiple ecosystem components can be integrated in holistic evaluations (Borja et al., 2014) and a review of currently available methods to undertake such integrated assessments (Borja et al., 2016). In addition, we present the innovative basis for a new assessment tool (Andersen et al., 2014) and this new tool (Nested Environmental status Assessment Tool: NEAT) was tested in 10 case studies across all European seas (Uusitalo et al.).

Sixthly, we emphasize that the socio-economic perspective of this work deserves attention as well as the ability of marine habitats to provide ecosystem services, which in turn provide societal benefits, as presented by Galparsoro et al. (2014). Furthermore, there is the need to assess the cost and benefits of measures to achieve Good Environmental Status (Börger et al.) and to determine and present the value of marine monitoring (Nygård et al.).

All of the above emphasize that scientific understanding and research is only valuable once disseminated to its users,

\section{REFERENCES}

Andersen, J. H., Dahl, K., Göke, C., Hartvig, M., Murray, C., Rindorf, A., et al. (2014). Integrated assessment of marine biodiversity status using a prototype indicator-based assessment tool. Front. Mar. Sci. 1:55. doi: 10.3389/fmars.2014.00055

Borja, A. (2014). Grand challenges in marine ecosystems ecology. Front. Mar. Sci. 1:1. doi: 10.3389/fmars.2014.00001

Borja, A., Elliott, M., Andersen, J. H., Berg, T., Carstensen, J., Halpern, B. S., et al. (2016). Overview of integrative assessment of marine systems: the Ecosystem Approach in practice. Front. Mar. Sci. 3:20. doi: 10.3389/fmars.2016. 00020

Borja, A., Prins, T., Simboura, N., Andersen, J. H., Berg, T., Marques, J. C., et al. (2014). Tales from a thousand and one ways to integrate marine ecosystem components when assessing the environmental status. Front. Mar. Sci. 1:72. doi: 10.3389/fmars.2014.00072 especially those beyond the scientific community and because of this we emphasize the need to improve the two-way knowledge transfer between researchers and policy makers. Therefore, we present ways to enhance the effectiveness of research results communication (Mea et al.) and show how DEVOTES has contributed to filling in the gaps between policy and science for assessing the health status of marine systems, including the main challenges for the future (Borja et al.).

This ebook with its extensive collection of papers is aimed at scientists and policy makers and implementers, at educators needing to communicate such up to date aspects to the next generation of scientists and policy makers, and at industry which has to respond to the requirements of marine policy. Although the contributions are the result of a European project with predominantly European workers, we consider that the findings, lessons and messages will be of high relevance to those working in other geographical systems and areas. We hope that all readers of this eBook will find the collection of peer-reviewed papers useful in their daily work, through selecting appropriate indicators, implementing and improving monitoring networks, modeling marine systems, or assessing the status in an integrative way. As such, we hope that this eBook conveys and disseminates the outcome of the DEVOTES collaborative and multidisciplinary work to a broad audience, including scientists, policy-makers, environmental managers, stakeholders and the public in general. Although bridging science and policy will always remain a challenge, our hope is that with this eBook the gap has been reduced. We thank all the contributors and are confident that you will enjoy reading these papers as much as we did writing them!

\section{AUTHOR CONTRIBUTIONS}

$\mathrm{AB}$ wrote the first draft and then all co-authors contributed equally to the final draft.

\section{FUNDING}

This editorial is a result of DEVOTES (DEVelopment Of innovative Tools for understanding marine biodiversity and assessing good Environmental Status) project, funded by the European Union under the 7th Framework Programme, "The Ocean of Tomorrow" Theme (grant agreement no. 308392), http://www.devotes-project.eu.

Carstensen, J. (2014). Need for monitoring and maintaining sustainable marine ecosystem services. Front. Mar. Sci. 1:33. doi: 10.3389/fmars.2014.00033

Galparsoro, I., Borja, A., and Uyarra, M. C. (2014). Mapping ecosystem services provided by benthic habitats in the European North Atlantic Ocean. Front. Mar. Sci. 1:23. doi: 10.3389/fmars.2014.00023

Conflict of Interest Statement: The authors declare that the research was conducted in the absence of any commercial or financial relationships that could be construed as a potential conflict of interest.

Copyright (C) 2017 Borja, Elliott, Uyarra, Carstensen and Mea. This is an open-access article distributed under the terms of the Creative Commons Attribution License (CC $B Y)$. The use, distribution or reproduction in other forums is permitted, provided the original author(s) or licensor are credited and that the original publication in this journal is cited, in accordance with accepted academic practice. No use, distribution or reproduction is permitted which does not comply with these terms. 